\title{
Investigation of hydration products of fly ash-slag pastes
}

\author{
Zbigniew Kledyński $^{1} \cdot$ Agnieszka Machowska $^{1} \cdot$ Barbara Pacewska $^{2} \cdot$ \\ Iwona Wilińska ${ }^{2}$
}

Received: 30 November 2016/Accepted: 22 February 2017/Published online: 8 March 2017

(c) The Author(s) 2017. This article is published with open access at Springerlink.com

\begin{abstract}
The paper presents the results of the research identifying the hydration products present in hardened fly ash-slag pastes considered as alternative non-clinker binder. Thermal analysis (TG/DTG), infrared spectroscopy (FTIR) and scanning electron microscopy (SEM) were used as complementary methods. The pastes contained the binder made of two components: fly ash from circular fluidized bed combustion of brown coal and ground granulated blast furnace slag. The components were mixed accordingly to five formulas differing in proportions, but with constant water/binder ratio $(w / b=0.5)$. No chemical activators were used to initiate the binding reaction of blast furnace slag. The results of thermal analysis, IR spectroscopy and scanning electron microscopy as well as the increase of compressive and flexural strength in time revealed the progression of hydration process in time and formation of products similar to ones present in hardened cement pastes. SEM observations of pastes after 90 days of curing showed fibrous (type I) and similar to honeycomb form of $\mathrm{C}-\mathrm{S}-\mathrm{H}$ phase, ettringite and calcium aluminates.
\end{abstract}

Keywords Fly ash · Slag $\cdot$ Non-clinker binders $\cdot$ Hydration products $\cdot$ TG/DTG $\cdot$ FTIR

Agnieszka Machowska

agnieszka.machowska@is.pw.edu.pl

1 Faculty of Building Services, Hydro and Environmental Engineering, Warsaw University of Technology, 20 Nowowiejska Str., 00-653 Warsaw, Poland

2 Faculty of Civil Engineering, Mechanics and Petrochemistry, Institute of Chemistry, Warsaw University of Technology, 17 Łukasiewicza Str., 09-400 Płock, Poland

\section{Introduction}

Necessity of limiting the emission of $\mathrm{CO}_{2}$ generated by industrial activity of man, and also other ecological and economic reasons cause that the new solutions in the range of cement production are investigated in accordance with climatic policy and circular economy. Different fine-grained materials, including some mineral waste, have been used as cement components or additions for concrete for decades. There are several benefits of such activity: possibility of reduction of production of clinker and thus reduction of emission of $\mathrm{CO}_{2}$, saving energy and natural resources, utilization of waste material as well as production of cement binder of modified properties. There is great interest in composites containing high amount (50\% and higher) of cement replacements. For example, attempts of incorporating various additives in cement pastes, such as siliceous fly ash, metakaolin or slag, were presented in works [1-3]. The additives have a significant impact on lowering the heat of hydration and the rate of heat evolution of composite binders. In case of low-calcium fly ash, lengthening of induction period and reduction of intensity of acceleration period are observed. The more of such component is added, the stronger the effects are observed [1, 2, 4].

The challenge for engineers and scientists is to obtain alternative non-clinker binders performing parameters at least close to parameters of Portland cement, which is now the most popular binding material. Different aluminosilicate materials may be used as a source material for this purpose [5]. However, they usually need strong alkaline activation for hardening and often also elevated temperature [6-8]. It generates problems, inter alia, with safety of workers as well as environmental protection.

New alternative non-clinker binders composed of ground granulated blast furnace slag and fly ash from 
fluidized coal combustion, without additional alkaline activators, seem to be a good perspective.

Fly ash from conventional coal combustion is commonly used in cement and concrete production. Its properties have been widely investigated, and this type of fly ash was standardized as a component of concrete [9]. Ecologically friendly process of fluidized combustion is nowadays more often applied, but fly ash produced is not used in cement and concrete technology due to significantly different properties compared to conventional fly ash, among the others, high water demand and high specific surface of grains presenting irregular shape [10]. However, thanks to high amount of calcium compounds (i.e. mainly anhydrous $\mathrm{CaSO}_{4}$ and $\mathrm{CaO}$ ) and also aluminosilicate structure, fly ash from fluidized combustion reveals binding properties after mixing with water [11-14]. Also blast furnace slag, when finely ground and chemically activated, presents hydraulic properties and microstructure rich in phases characteristic of Portland cement composites, but of higher water tightness and resistance to aggressive agents impact $[7,15,16]$.

Using mixture of fluidized fly ash and slag, as nonclinker binder, one makes use of self-cementing properties of fly ash and activating action of its components (especially $\mathrm{Ca}(\mathrm{OH})_{2}$ and $\left.\mathrm{CaSO}_{4}\right)$ on slag grains $[1,3,17]$. There is a little information in the literature about such utilization of these waste materials describing mechanism of chemical processes of hardening and properties of final composite. More information is found about alkaline activated compositions of conventional fly ash and slag $[5,18]$. It should be emphasized that fluidized fly ashes from different combustion installations may vary significantly in their composition. For example, fly ash used in [19] contained a lot more of $\mathrm{SO}_{3}$ and $\mathrm{CaO}$ as compared with fly ash used in this work. Thus, one may expect that hydration processes, activating action and development of properties of fly ashslag binders in these cases will be also different.

It is well known that the properties of final binding material depend on complex chemical and physical processes taking place within this composition. Therefore, in case of any new composite material, it is extremely important to conduct the research of hydration process and products along with mechanical properties investigation.

The preliminary research of mortars based on nonclinker binder composed of fly ash from circular fluidized coal combustion and ground granulated blast furnace slag was conducted [20]. The fly ash, before being mixed in mortars, was mechanically activated and displayed a very good stability of chemical parameters [21]. The results of mechanical tests were advantageous and showing potential possibility of applying this type of binder in mortars. Favourable results of preliminary tests were the base for physicochemical research of hydration process.
This paper presents the results of TG/DTG, IR and SEM-EDX as well as strength tests of fly ash-slag pastes after 28 and 90 days of curing. The aim of the conducted research was to identify the hydration products and mechanical parameters of the above-mentioned pastes to be estimated if such compositions might be used as nonclinker binders and are worth further studies. Investigation of hydration products and properties of new, non-clinker binders is essential to increase the level of by-products application in cement and concrete technology.

\section{Experimental}

\section{Materials}

Pastes were prepared using non-clinker binder composed of ground granulated blast furnace slag (ggbfs) and fly ash from circular fluidized bed combustion (CFBC) of brown coal. CFBC fly ash used in experiments revealed, among the others, high water demand (111\% acc. to EN 450-1). Therefore, it underwent the process of mechanical activation resulting in separating the conglomerates of ash fractions and refreshing grains' surfaces without changing their dimensions [22]. Binders were mixed with water in five proportions of dry components (slag/fly ash) with constant water/binder ratio $w / b=0.5$ (Table 1 ). No chemical activators were used to initiate the binding reaction of ggbfs. XRD patterns of ggbfs and CFBC fly ash are presented in Figs. 1, 2.

The samples for mechanical tests (three for each formula and test) were prepared in prismatic moulds of $40 \times 40 \times 160 \mathrm{~mm}$. After $24 \mathrm{~h}$ of setting, the samples were taken out of moulds and kept in water of temp. $20 \pm 1{ }^{\circ} \mathrm{C}$ for 28 and 90 days, respectively. Before the laboratory tests, the samples were taken out of water, wiped out of water, measured and weighed. These pastes were also used for TG/DTG, IR and SEM analyses (samples were taken from the central parts of the hardened pastes). Before TG/DTG and IR measurements hydration was stopped by the use of acetone.

Table 1 Proportions of dry components of investigated pastes (mass \%)

\begin{tabular}{llllll}
\hline Formula & 1 & 2 & 3 & 4 & 5 \\
\hline CFBC fly ash & 30 & 40 & 50 & 60 & 70 \\
Ggbfs & 70 & 60 & 50 & 40 & 30 \\
\hline
\end{tabular}

Chemical composition of applied materials (\% by mass) is given in Table 2 
Table 2 Chemical composition of ggbfs and CFBC fly ash (mass \%)

\begin{tabular}{lrr}
\hline Component & \multicolumn{1}{c}{ Slag } & Fly ash \\
\hline $\mathrm{SiO}_{2}$ & 36.27 & 34.87 \\
$\mathrm{Al}_{2} \mathrm{O}_{3}$ & 9.15 & 23.09 \\
$\mathrm{CaO}$ & 45.15 & 21.10 \\
$\mathrm{CaO}_{\text {free }}$ & 0.80 & 7.00 \\
$\mathrm{Fe}_{2} \mathrm{O}_{3}$ & 1.55 & 4.82 \\
$\mathrm{SO}_{3}$ & 0.67 & 5.66 \\
$\mathrm{MgO}$ & 5.86 & 1.69 \\
$\mathrm{Na}_{2} \mathrm{O}$ & 0.01 & 0.02 \\
$\mathrm{~K}_{2} \mathrm{O}$ & 0.05 & 0.01 \\
$\mathrm{P}_{2} \mathrm{O}_{5}$ & 0.69 & 3.81 \\
$\mathrm{Cl}^{-}$ & 0.11 & 0.04 \\
$\mathrm{LOI}$ & 0.00 & 3.15 \\
\hline
\end{tabular}

\section{Test methods}

Thermogravimetric studies (TG/DTG) were conducted using thermoanalyser SDT 2960 (TA Instruments). Mass of a sample was $10-17 \mathrm{mg}$, and measurement was taken in nitrogen atmosphere, at constant temperature raise equal to $10{ }^{\circ} \mathrm{C} \mathrm{min}^{-1}$.

Investigation of hydration products with means of IR spectroscopy was conducted in spectrophotometer Genesis II FTIR (Mattson), within the range of spectra: $4000-400 \mathrm{~cm}^{-1}$. The samples were prepared in the form of $\mathrm{KBr}$ pellets.

SEM observations of microstructure were conducted in scanning electron microscope ZEISS LEO 1430, equipped in detector of energy dispersion (EDS) Oxford ISIS 300, (Oxford Instruments). Small pieces of pastes were taken
Fig. 1 XRD pattern of CFBC fly ash

Fig. 2 XRD pattern of slag
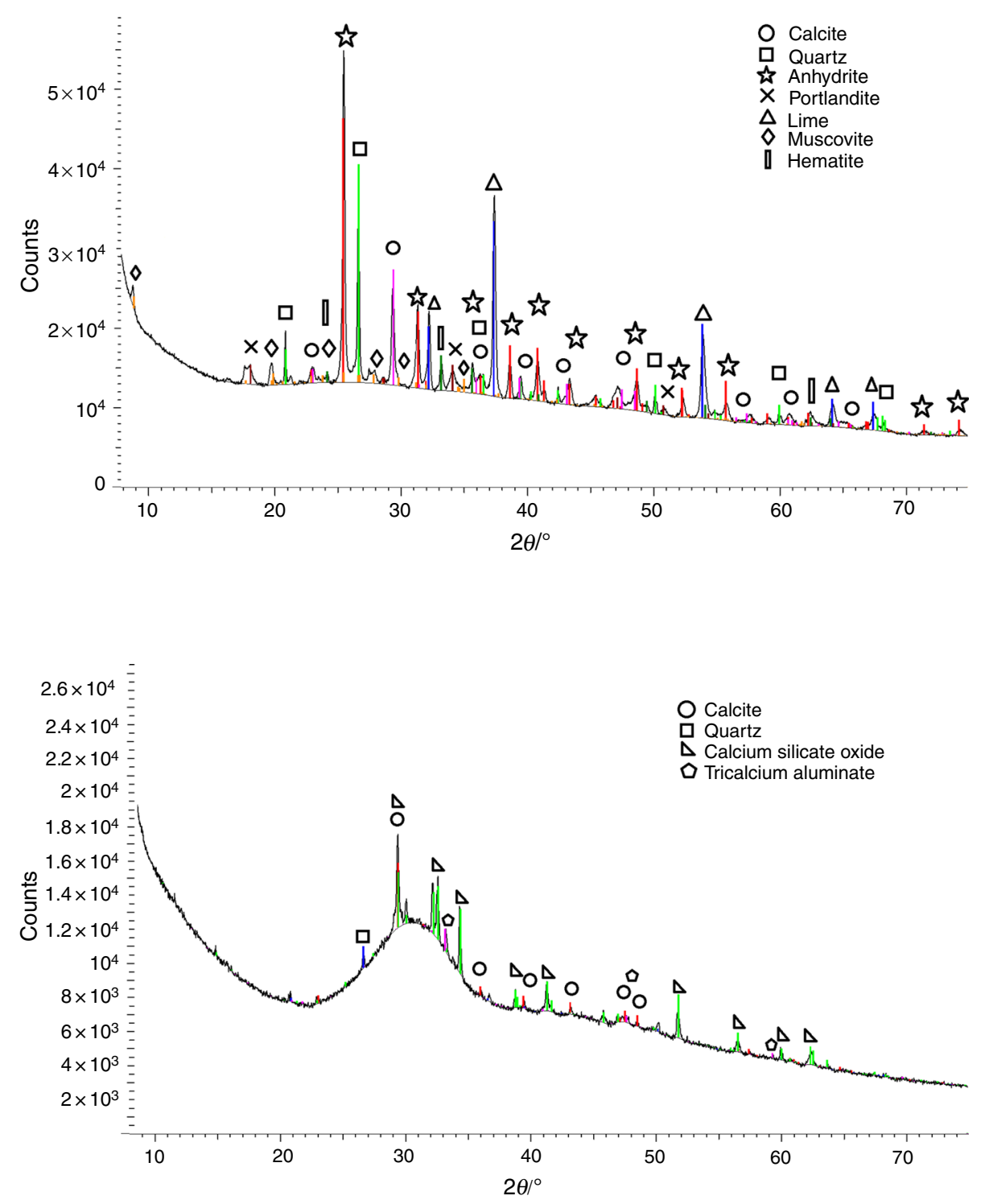
from the bars, dried and placed on the holder, transferred to the coater and covered with thin gold layer, then observed in low vacuum mode at $6 \times 10^{-5}-7 \times 10^{-6}$ Torr, at acceleration voltage of $20 \mathrm{kV}$ and current of $80 \AA$. Current on sample's surface is 84-143 pA.

Flexural and compressive strength of prismatic samples of fly ash-slag pastes after 28 and 90 days of curing were carried out according to EN 196-1 [23]. Before the tests, each sample was measured and weighed.

\section{Results and discussion}

\section{Thermal analysis results}

The results of TG/DTG investigation of samples after 28 and 90 days of hydration are presented in Fig. 3 (TG and DTG curves). Mass losses in selected ranges of temperature, obtained from TG curves, are presented in Fig. 4.
Fig. 3 TG and DTG curves of fly ash-slag pastes registered after 28 and 90 days of hydration, a-e results for pastes $1-5$, respectively (a)

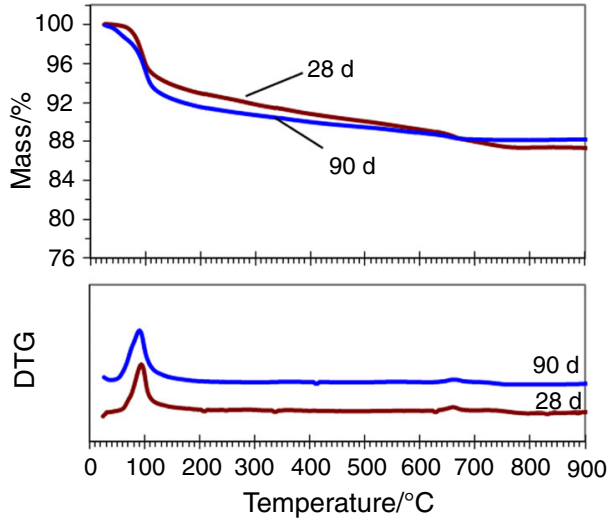

(c)
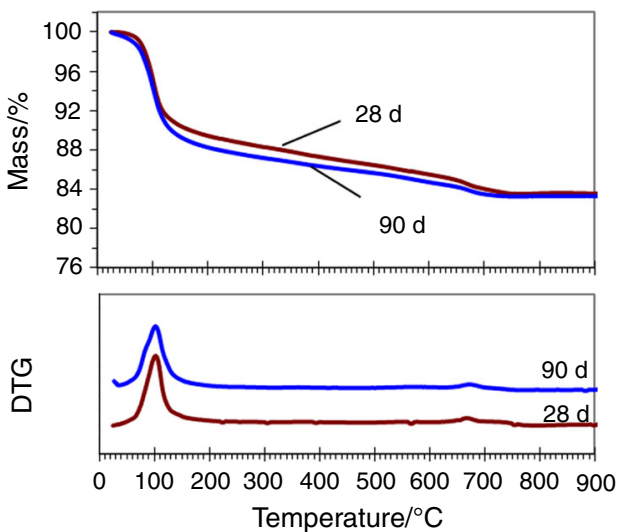

(e)
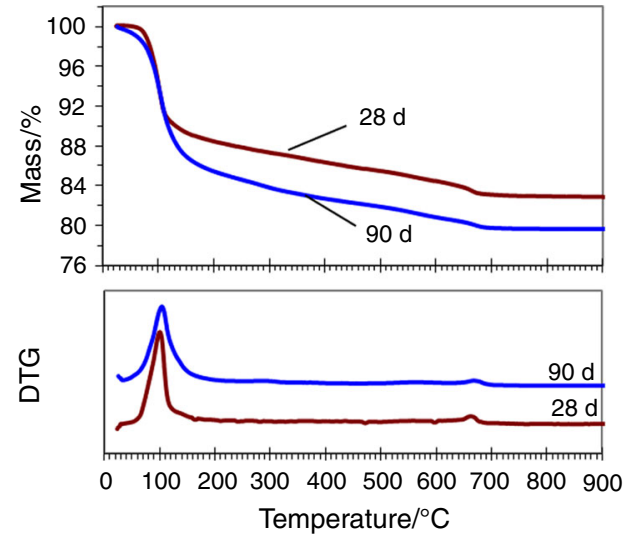

(b)

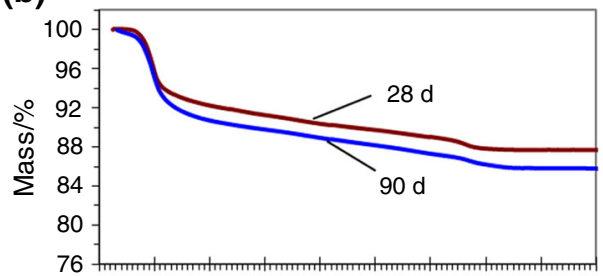

$\stackrel{5}{5}$

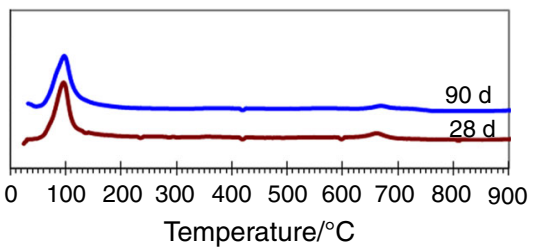

(d)
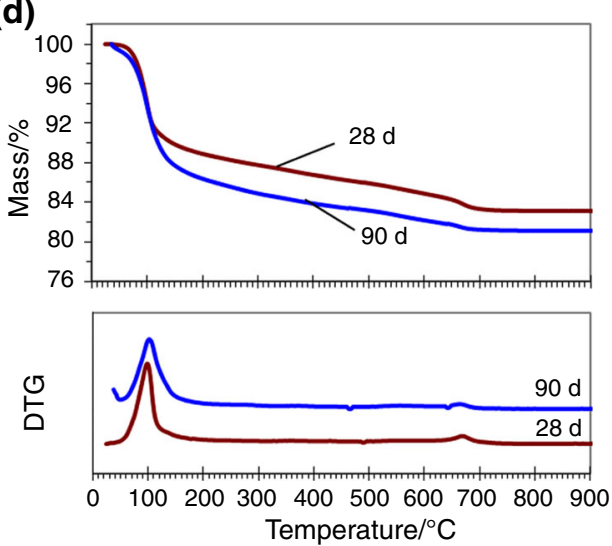
(a)

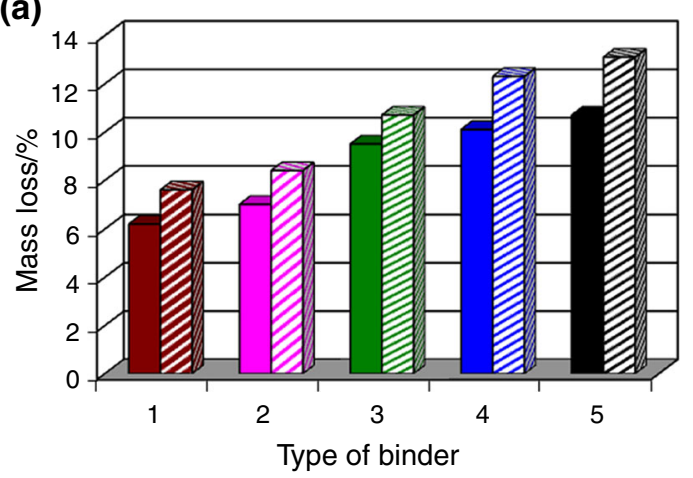

(b)

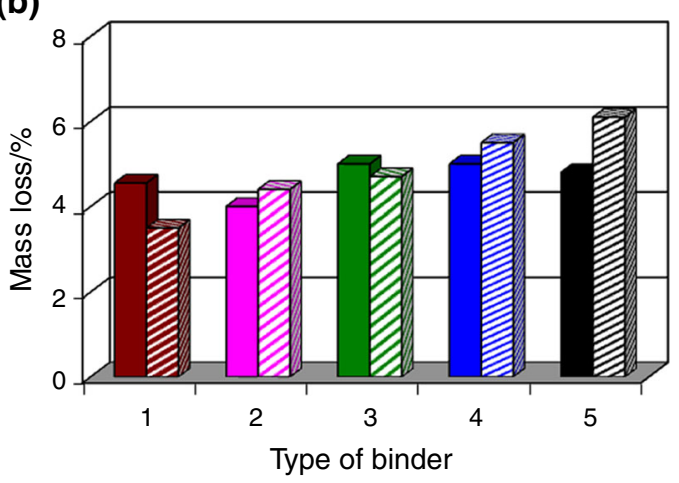

(c)

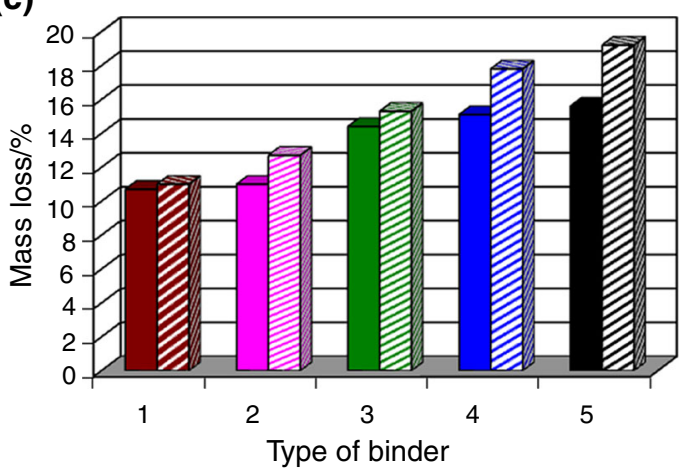

Fig. 4 Mass losses of fly ash-slag pastes in selected temperature ranges (a $20-150{ }^{\circ} \mathrm{C}$, b $150-600{ }^{\circ} \mathrm{C}$, c $20-600{ }^{\circ} \mathrm{C}$ ) after 28 and 90 days of hydration (hatching -90 days of hydration)

TG and DTG curves of all samples reveal continuous mass loss connected with dehydration of hydrated forms. Shapes of TG and DTG curves for fly ash-slag pastes are very similar, indicating that qualitative compositions of samples are also similar regardless of the proportions of ggbfs and fly ash in binder and related time of hydration, but different quantitative compositions. The main mass loss is noticed in temperatures up to $150{ }^{\circ} \mathrm{C}$ with extreme value near $100{ }^{\circ} \mathrm{C}$ on DTG curves. This indicates that main products of hardened samples are hydrated calcium silicates type of $\mathrm{C}-\mathrm{S}-\mathrm{H}^{1}$ and sulphoaluminates (ettringite). In

\footnotetext{
${ }_{1}$ Abbreviations used in cement chemistry: $\mathrm{C}-\mathrm{CaO}, \mathrm{S}-\mathrm{SiO}_{2}, \mathrm{H}-\mathrm{H}_{2} \mathrm{O}$, $\mathrm{A}-\mathrm{Al}_{2} \mathrm{O}_{3}$.
}

higher temperatures, further mass loss takes place (up to $600{ }^{\circ} \mathrm{C}$ ) without distinguishing separate effects on DTG curves. This mass loss is related to dehydration of more thermally stable hydrates, such as hydrated calcium aluminates and aluminosilicates $(\mathrm{C}-\mathrm{A}-\mathrm{H}$ and $\mathrm{C}-\mathrm{A}-\mathrm{S}-\mathrm{H}$ phases) and also aluminosilicate phases containing magnesium. In above-mentioned range of temperatures, carboaluminates may also decompose. The amount of these products increases in time of hydration especially in pastes containing more CFBC fly ash. It indicates higher amount of water evaporating within the range of temperatures $150-600{ }^{\circ} \mathrm{C}$ and resulting in shape of DTG curve (visible peak extension on 90th day of hydration comparing to 28th day), also quantities of mass loss. Despite the fact that main mass losses of considered phases, resulting from dehydration, take place in mentioned ranges of temperature, the

(a)

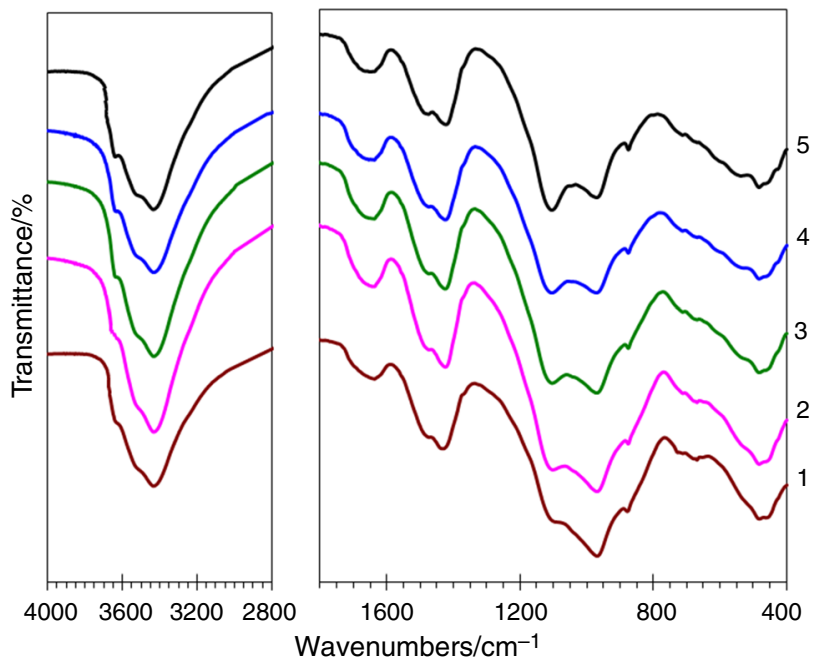

(b)

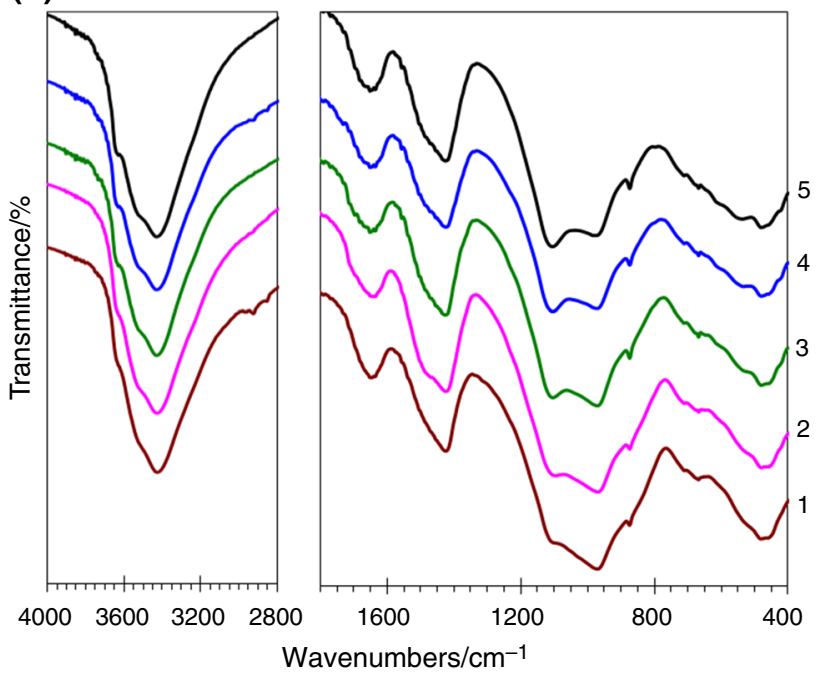

Fig. 5 IR spectra for fly ash-slag pastes after 28 (a) and 90 (b) days of hydration (1-5-type of binder) 
total dehydration of clean phases takes place in wider range of temperature. For example, as shown in thermal test results in the article [24], C-S-H phase undergoes dehydration in temperatures up to $600{ }^{\circ} \mathrm{C}$, similarly to $\mathrm{C}_{2} \mathrm{ASH}_{8}$, but the main mass loss of $\mathrm{C}-\mathrm{S}-\mathrm{H}$ phase is up to $200{ }^{\circ} \mathrm{C}$, and for strätlingite in about $200{ }^{\circ} \mathrm{C}$. Mass loss in temp. between 600 and $700{ }^{\circ} \mathrm{C}$ is the result of carbonates decomposition.

The increase of bound water amount in hydrated forms indicates the progression of hydration processes. Analysis of TG/DTG curves shapes shows that in case of formulae with lower amount of fly ash, main chemical processes resulting in binding of water took place till 28th day of hydration. It is confirmed by little increase in bound water amount after that period of time. For samples containing 60 and $70 \%$ of CFBC fly ash and 40 and $30 \%$ of ggbfs, respectively, in dry binder (formulae 4 and 5), it is noticed that later water binding in structure takes place also between 28th and 90th day of hydration, despite lack of $\mathrm{Ca}(\mathrm{OH})_{2}$ in the system. The shapes of TG/DTG curves registered for all examined formulae reveal that clear mass loss of $\mathrm{Ca}(\mathrm{OH})_{2}$ in temperature $450-500{ }^{\circ} \mathrm{C}$ is not observed despite that gradual mass reduction of samples takes place up to $700{ }^{\circ} \mathrm{C}$. Calcium hydroxide is present in composition mainly due to CFBC fly ash, as $\mathrm{Ca}(\mathrm{OH})_{2}$ and also $\mathrm{CaO}$, which undergoes hydration in the presence of water (Table 2; Fig. 1). Lack of confirmation of $\mathrm{Ca}(\mathrm{OH})_{2}$ presence in pastes shows that it reacted in pozzolanic reaction in first 28 days of hydration. $\mathrm{Ca}^{2+}$ ions may be also released to reaction environment from calcium components of ggbfs due to its dissolution in alkaline environment. Highly alkaline nature of extracted solutions of binder's components (slag solution: $\mathrm{pH}=12,4$, CFBC fly ash solution: $\mathrm{pH}=12,7$ ) dissolves aluminosilicate grains of fly ash and slag. As a result, silicate and aluminate ions appear in solution where they undergo further reactions, among the others, forming calcium silicates of $\mathrm{C}-\mathrm{S}-\mathrm{H}$ type and calcium aluminates and aluminosilicates, and at adequate amount of sulphate ions-ettringite.

Increase of mass loss registered between 28th and 90th days of hydration, especially concerning samples 4 and 5, suggests that phases appearing in longer time of hydration may be poorer in calcium. $\mathrm{Ca}^{2+}$ ions may still be available to reaction due to dissolving of pastes components, but dissolubility ratio is not exceeded, so $\mathrm{Ca}(\mathrm{OH})_{2}$ is not precipitated in solid form. $\mathrm{Ca}^{2+}$ ions are diffused to the solution gradually. In early stage of hydration, $\mathrm{Ca}(\mathrm{OH})_{2}$ precipitates fast, mainly as a result of $\mathrm{CaO}$ hydration. Solution in pores reaches the $\mathrm{pH}$ value higher than 12 , which promotes dissolution of aluminosilicate components of pastes. Some of $\mathrm{CaO}$ entering with fly ash is for some time unavailable for reaction, because it is covered with layer of hardly soluble $\mathrm{CaSO}_{4}$ and $\mathrm{Ca}(\mathrm{OH})_{2}$ [25].

Amount of water bound in hydrates highly depends on availability of sulphate ions. Pastes with lower amount of anhydrite (lower amount of fluidized fly ash) exhibit lower mass loss registered in temp. up to $600{ }^{\circ} \mathrm{C}$ which indicates formation of products containing less water, i.e. $\mathrm{C}_{4} \mathrm{AH}_{13}$,
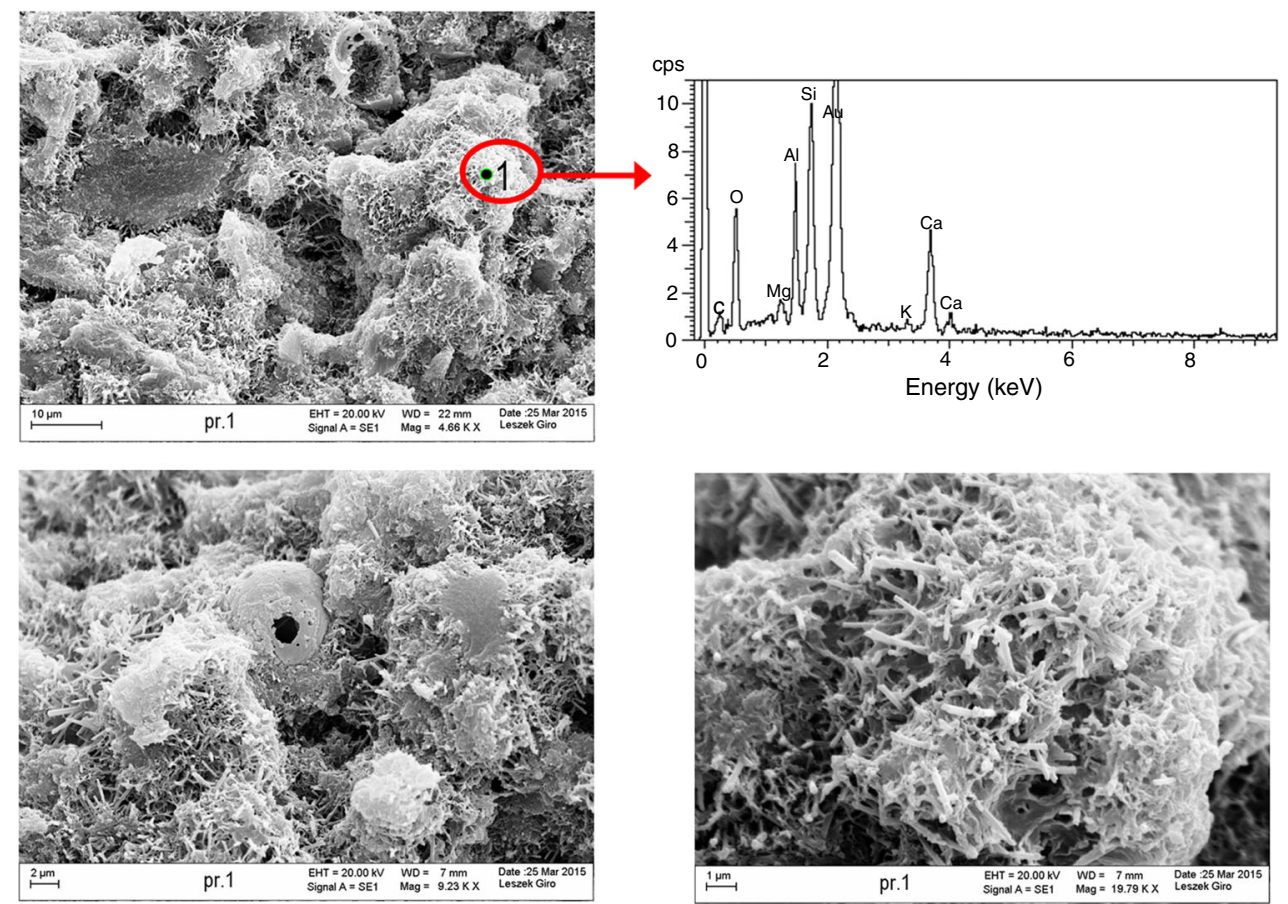

Fig. 6 Microstructure of formula 1 and elemental spectrum of selected phase (fibrous form and dense agglomerates of C-S-H phase, visible not reacted fly ash grain) 

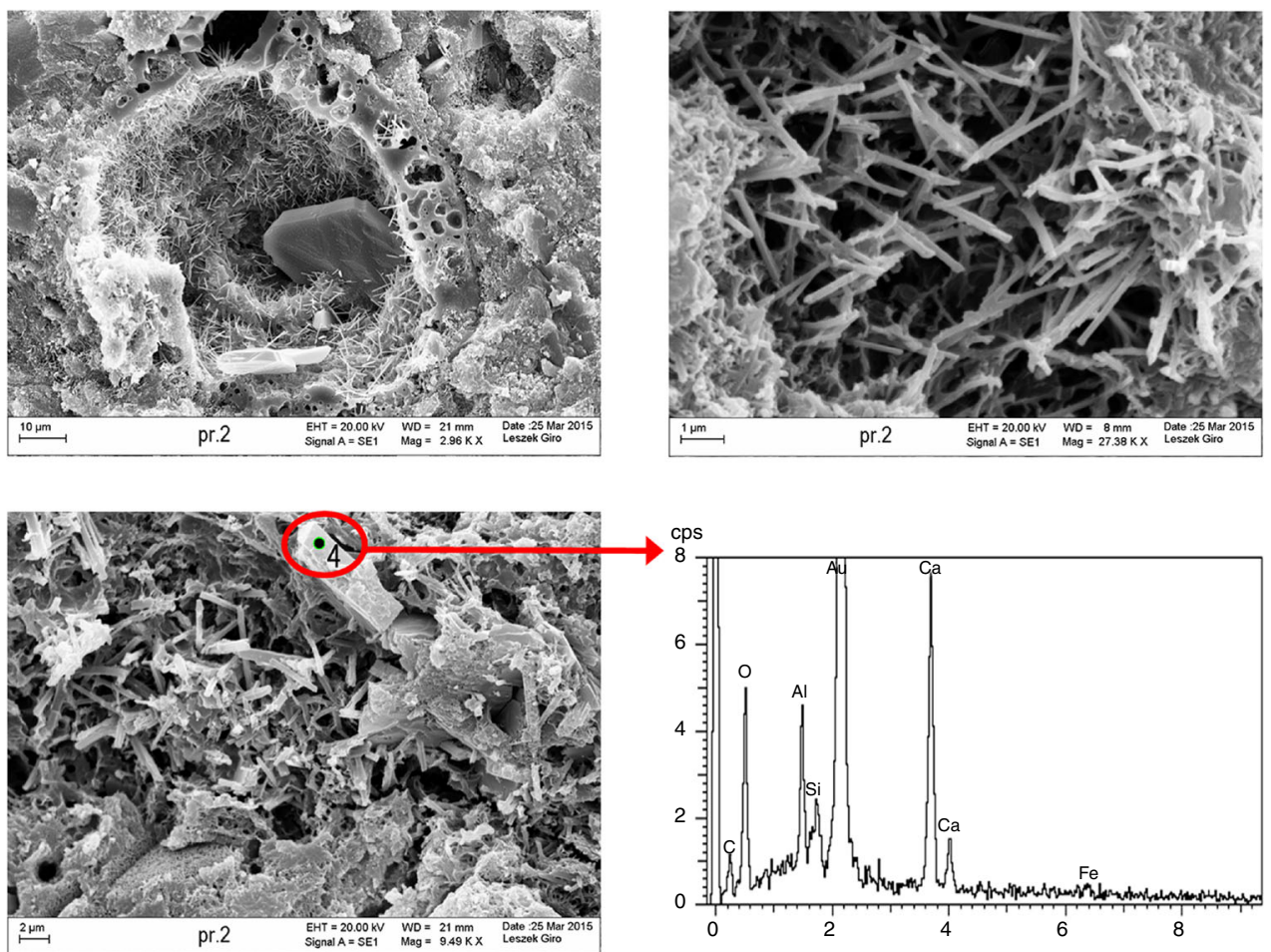

Fig. 7 Microstructure of formula 2 and elemental spectrum of selected phase (fibrous form and dense agglomerates of C-S-H phase, calcium aluminosilicate forms)

while higher sulphate concentration in solution favours formation of ettringite with higher amount of bound water [26].

Fly ash from fluidized coal combustion reveals binding properties, so it can be expected that in samples containing the highest amount of fly ash (50\% and more-pastes 3, 4 and 5), especially in early periods of hydration, it contributes in binding and hardening of pastes. It can be assumed that the binding mechanism of such mixes is responsible for creation of $\mathrm{C}-\mathrm{S}-\mathrm{H}$ phase as a result of reaction of calcium compounds with reactive silica and forming ettringite in reaction of active alumina or calcium aluminate with gypsum and lime [25].

In later periods of hydration, hydrated compounds with ions different from calcium ions, such as hydrotalcite-like phases, and containing relatively high amount of bound water may also be created [24, 28-30].

Analysing the reasons of presence of higher amounts of water in samples along with increasing amount of fly ash, it shall be noticed that possibility of water sorption in porous structure of $\mathrm{C}-\mathrm{S}-\mathrm{H} / \mathrm{C}-\mathrm{A}-\mathrm{S}-\mathrm{H}$ phase may not be excluded.

\section{Infrared spectroscopy results}

Figure 5 presents IR spectra of examined mixes, which were registered after 28 and 90 days of hydration. Similar shapes of IR spectra after these periods of time confirm earlier findings (TG/DTG results) that the processes of hydration are most intense up to 28th day of hydration. After this time, the changes in shapes of spectra are not significant.

Intense, broad band with extreme value near $3430 \mathrm{~cm}^{-1}$ reveals the presence of water (stretching vibrations of $\mathrm{H}-$ $\mathrm{O}-\mathrm{H})$ bound in different types of hydrates. Lack of visible sharp band at $3640 \mathrm{~cm}^{-1}$ confirms conclusions drawn from thermal analysis concerning lack of $\mathrm{Ca}(\mathrm{OH})_{2}$ in composition. It means that $\mathrm{Ca}(\mathrm{OH})_{2}$ reacted till 28th day of hydration. Only samples with higher amount of fly ash (formulae 3-5) on 28th day of hydration reveal slight band near $3630 \mathrm{~cm}^{-1}$, which may indicate traces of $\mathrm{Ca}(\mathrm{OH})_{2}$ undetectable in TG/DTG tests. This band may be also connected with the presence of ettringite [31, 32]. Moderately intense band of deformation vibrations of water particles is placed near $1640 \mathrm{~cm}^{-1}$ in IR spectra. It is quite broad, and its extreme migrates towards slightly lower wave lengths with time of hydration and along with increase of CFBC fly ash amount in pastes (i.e. after 28 days of hydration extreme is placed near $1638 \mathrm{~cm}^{-1}$ in case of formulae $1-3$, and near 1645 and $1650 \mathrm{~cm}^{-1}$ in case of formulae 4-5; after 90 days of hydration$1647 \mathrm{~cm}^{-1}$ in case of formula 1 and $1652 \mathrm{~cm}^{-1}$ in case of formula 5). Precise analysis of discussed band's location 

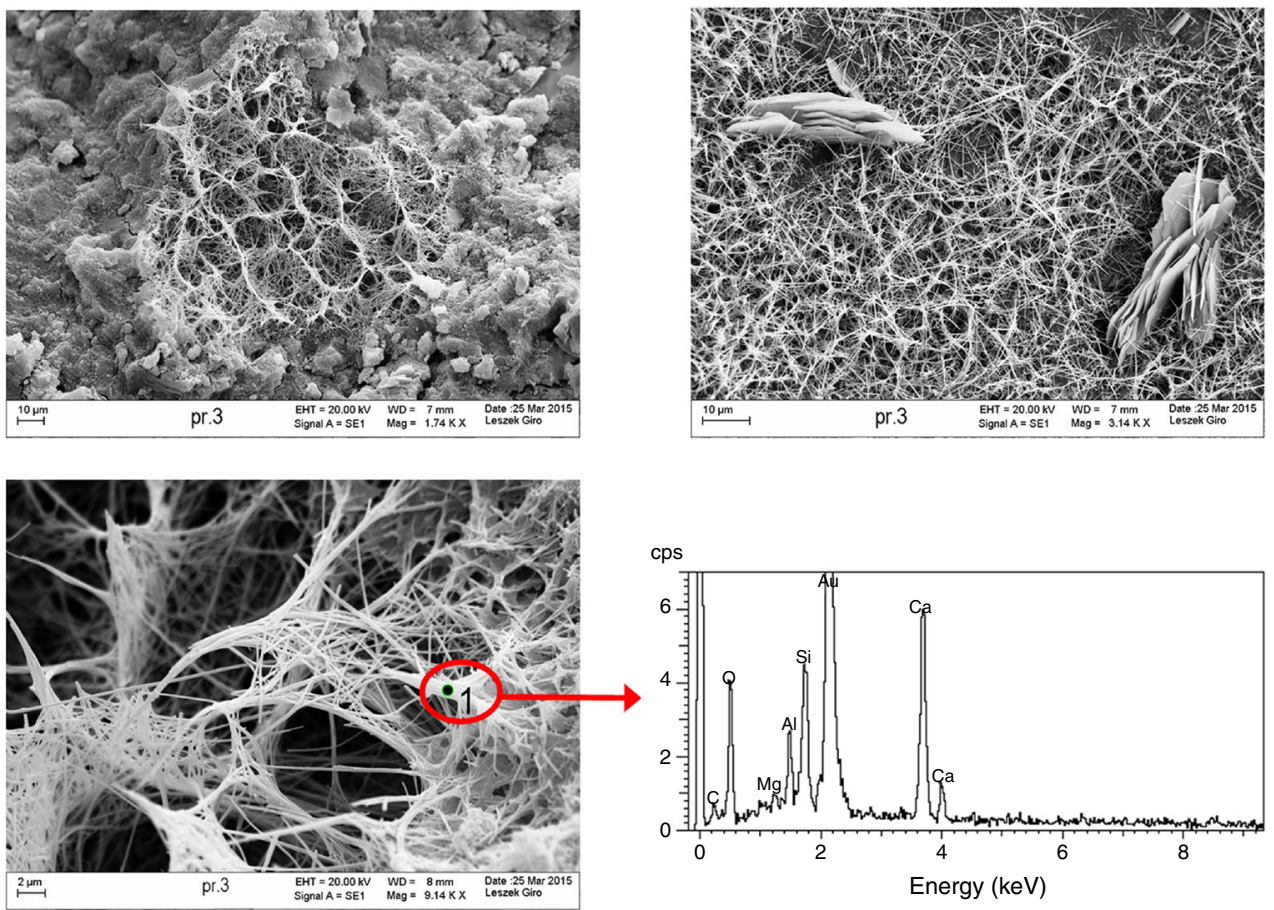

Fig. 8 Microstructure of formula 3 and elemental spectrum of selected phase (fibrous forms growing in pores and connected in network, visible aluminosilicate products in the form of plates)

and shape reveals that samples with lower amount of fly ash (formulae 1 and 2) show clear extreme, while in samples with higher amount of fly ash this extreme is slightly more broadened. It may be caused by ettringite presence which, in case of pure phase, presents two bands: near 1640 and $1675 \mathrm{~cm}^{-1}$ [31]. Complexity of pastes composition (different types of hydrated phases) causes that the range of wavenumbers characteristic of stretching and deformation vibrations bands of $\mathrm{H}-\mathrm{O}-\mathrm{H}$ particles is difficult to interpret in detail due to bands overlapping.

Clear intense band with extreme near $970 \mathrm{~cm}^{-1}$ confirms formation of $\mathrm{C}-\mathrm{S}-\mathrm{H}$ phase in all investigated pastes.

Moderately intense, broad band within the range of wavenumbers $1350-1550 \mathrm{~cm}^{-1}$ reveals carbonate phases. It is also confirmed by sharp band at $875 \mathrm{~cm}^{-1}$ and very weak band near $712 \mathrm{~cm}^{-1}$, but the last one may be caused by vibrations of $\mathrm{Si}-\mathrm{O}-\mathrm{Si}(\mathrm{Al})$ [33].

Shape of main band of carbonate groups vibrations and location of other bands indicate that carbonates occur in different polymorphous phases. Visible doublet in the range of wavenumbers $1350-1550 \mathrm{~cm}^{-1}$ indicates that on 28th day of hydration most probably calcite and vaterite are present in pastes [31]. In later periods, vaterite transforms into calcite [27, 34] confirmed by band with single extreme.

In IR spectra near $1100 \mathrm{~cm}^{-1}$ in all examined samples, there is a visible vibration band characteristic of sulphate phases. It is relatively weakly elicited in paste 1 , and its intensity increases with the increase of CFBC fly ash amount. Transfer of this band from $1120 \mathrm{~cm}^{-1}$ position characteristic of ettringite to about $1105 \mathrm{~cm}^{-1}$ may stand for a partial change of ettringite in monosulphate, but it cannot be explicitly confirmed due to lack of visible band at $1170 \mathrm{~cm}^{-1}$ [32]. Complex composition of samples, as in case of this work, along with overlapping of broad bands, makes it difficult to state if main stretching band of $\mathrm{S}-\mathrm{O}$ is a singlet (indicating for ettringite) or a doublet (indicating for monosulphate). Moreover, in analysed field of IR spectra bands of vibrations of $\mathrm{Si}-\mathrm{O}$ can be found, so this band may be also connected with the presence of not reacted fly ash in composition.

The absence of bands indicating anhydrite (near 595, 612 and $\left.680 \mathrm{~cm}^{-1}[35]\right)$, even in sample with the highest amount of fly ash, confirms that it underwent total reaction towards sulphoaluminate phases. Weak shoulder near $620 \mathrm{~cm}^{-1}$, visible in sample 5, may be connected with ettringite [36].

In case of all samples, weak band is noticeable near $669 \mathrm{~cm}^{-1}$, resulting from vibrations of $\mathrm{Si}-\mathrm{O}-\mathrm{Si}$ in $\mathrm{C}-\mathrm{S}-\mathrm{H}$ phase [37]. Bending vibrations band of $\mathrm{Si}-\mathrm{O}-\mathrm{Si}$ in tetrahedrons placed near $460 \mathrm{~cm}^{-1}$ undergoes division into weak doublet in time of hydration (separation of additional band near $480 \mathrm{~cm}^{-1}$ ) which may be the result of higher degree of $\mathrm{C}-\mathrm{S}-\mathrm{H}$ phase crystallization [38]. The band near 

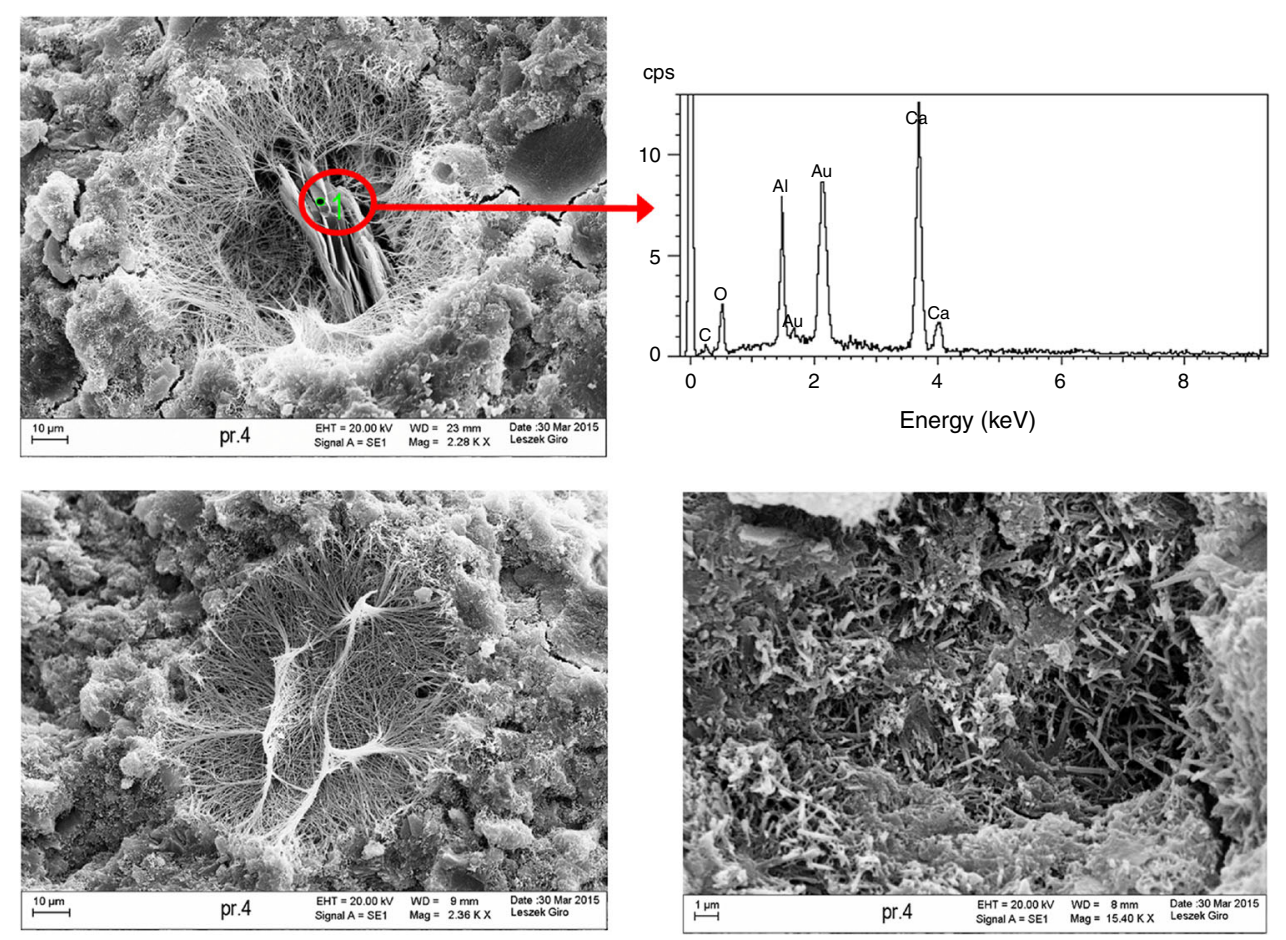

Fig. 9 Microstructure of formula 4 and elemental spectrum of selected phase (fibrous forms growing in pores, calcium aluminates in pores, visible cracks)

$460 \mathrm{~cm}^{-1}$ may also relate to vibrations of octahedrons $\mathrm{AlO}_{6}[31]$ in aluminate or aluminosilicate phases. In formulae 3,4 and 5, there is a visible band near $535 \mathrm{~cm}^{-1}$, which is more clear in longer time of hydration and with higher amount of fly ash. This band is probably related to vibrations of $\mathrm{AlO}_{6}$ in aluminate phases and ettringite [31]. Moreover, formulae 3, 4 and 5 in 90th day of hydration reveal very weak band near $420 \mathrm{~cm}^{-1}$ (in case of formula 5 , it is already visible in 28 th day of hydration). Similar changes of band's shape within the range $500-400 \mathrm{~cm}^{-1}$, that is weakly intense band at $488 \mathrm{~cm}^{-1}$ (band near $450 \mathrm{~cm}^{-1}$ ) as well as band at $425 \mathrm{~cm}^{-1}$, were also observed by authors [39], who investigated the products of alkaline activation of slag and fly ash from conventional combustion process.

\section{Investigations of microstructure by SEM-EDS}

The results of SEM-EDS tests are presented in Figs. 6-11. Microstructure of investigated fly ash-slag pastes is diversified and shows various forms of hydrates, including various forms of $\mathrm{C}-\mathrm{S}-\mathrm{H}$ phase. There are visible microsites with $\mathrm{C}-\mathrm{S}-\mathrm{H}$ phase in dense form, weakly crystallized, as well as dominating fibrous form of $\mathrm{C}-\mathrm{S}-\mathrm{H}$ phase which grows on spherical clusters. In some cases, fibres are connected regularly forming shapes similar to "honeycomb" type of $\mathrm{C}-\mathrm{S}-\mathrm{H}$ phase. Ettringite crystals appear mostly in the form of thin needles, growing in pores and filling them. This type of ettringite crystallization (in matrix pores) should not have a negative impact on strength of pastes, even if it takes place after the process of pastes hardening (crystallization of delayed ettringite). In case of sample with the highest amount of fly ash, resulting in highest amount of anhydrite entered into composition, ettringite in the form of crystallized bars is also noticeable. Hydrates of aluminates are observed in formulae 3-5. Aluminosilicate forms with magnesium are also visible. Formulae 3-5 exhibit growing number of pores within microstructure. The more of fly ash in pastes' composition, the higher number of microcracks is observed and less dense is the microstructure. Compared other formulae, sample 5 shows different microstructure, with fibrous forms appearing as short not connected needles. It also shows the presence of aluminosilicate hydrates, as well as ettringite in the form of bars and needles. More microcracks are observed in sample 5 .

\section{Mechanical strength of fly ash-slag pastes}

The results of compressive and flexural strength of fly ashslag pastes are shown in Fig. 12.

Compressive strength of examined pastes grows with increasing amount of fly ash and, in case of majority of samples, also in time of hydration. Intense strength 

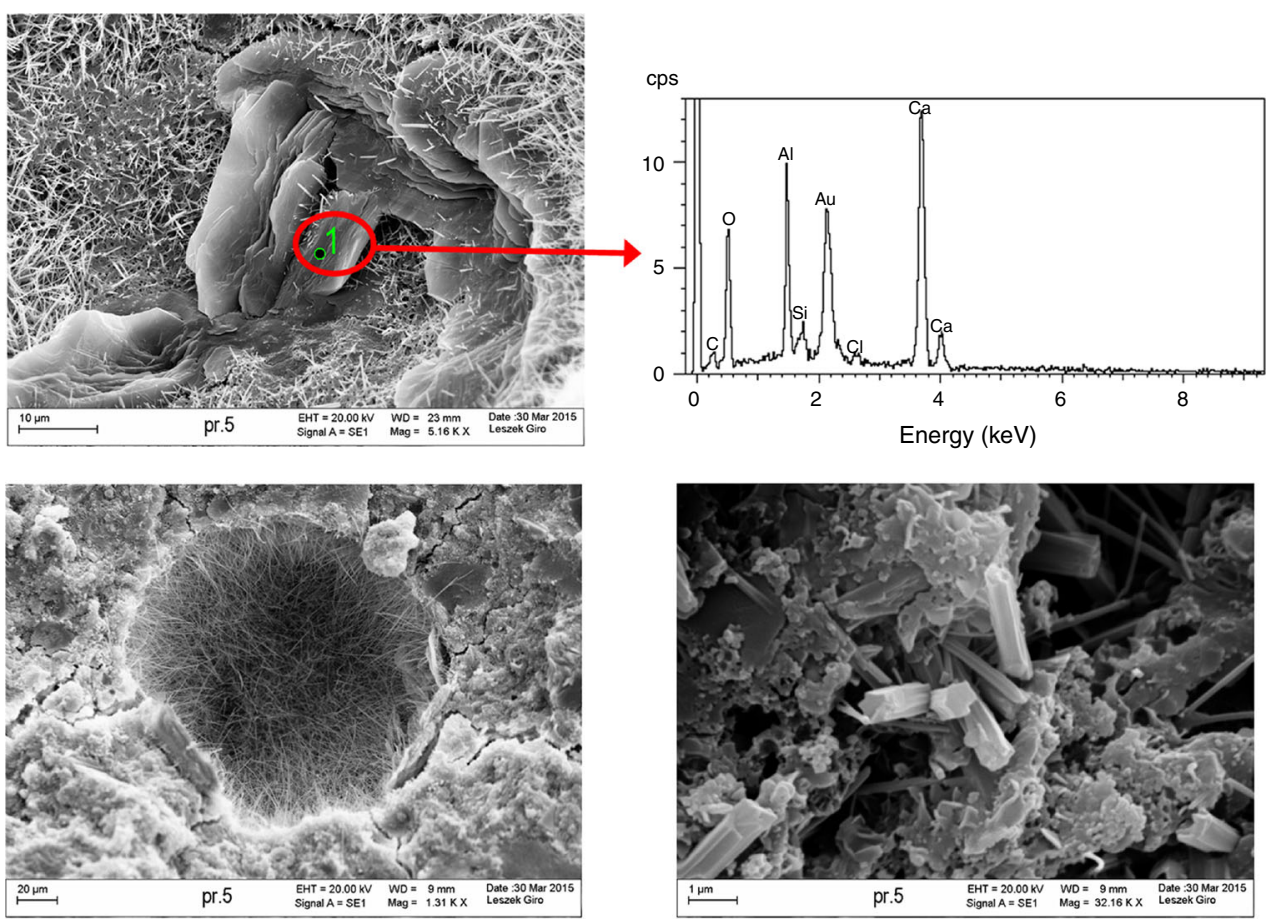

Fig. 10 Microstructure of formula 5 and elemental spectrum of selected phase (short not connected needles, calcium aluminate plates, ettringite needles growing in pores, ettringite in the form of bars precipitated in $\mathrm{C}-\mathrm{S}-\mathrm{H}$ phase)

development takes place up to 28 days of curing. Increase of samples' mechanical strength on 90th day of hydration is relatively low compared to the result obtained after 28 days. For example in 2-month time, between 28th and 90th day of hydration, compressive strength grows about $16 \%$ in case of sample 1 , about $6 \%$ in case of sample 4 , and decreases of about $6 \%$ in case of sample 5 . It confirms that strength development takes place mainly until 28th day of hydration and is connected strictly with physicochemical hydration processes, which result in forming phases showing binding properties. At the same time, the results of strength tests confirm conclusions drawn from thermal analysis and infrared spectroscopy investigation.

Decrease of compressive strength of pastes with the highest amount of CFBC fly ash finds its explanation in analysis of microscopic observations-more pores and microcracks in binder's matrix, as well as hydration products in form of short, disconnected needles and bars of crystallized ettringite in $\mathrm{C}-\mathrm{S}-\mathrm{H}$ phase were observed, compared to other formulae. It is possible that decrease of strength after 90th day of hydration, compared to strength after 28 days, is caused by formation of delayed ettringite in hardened material. In case of pastes with the highest amount of CFBC fly ash, the highest amount of anhydrite enters the composition. Slow process of anhydrite dissolution may cause late forming of delayed ettringite [27]. Increase of amount of bound water, which is observed on
TG/DTG curves of this sample after 90 days of hydration (the highest amount of bound water in comparison with other samples), is not reflected in higher strength of formula 5. Possibly, the amount of bound water is the result of ettringite presence or phases of little binding properties. However, it needs to be noticed that formula 5 exhibits the highest value of strength after 90 days of curing, compared to other samples. The same level of compressive strength is observed in formula 4. It indicates that microcracks of structure visible in SEM observations are not significant enough to reduce significantly material's mechanical strength. Favourably, in this sample ettringite is mainly present in pores.

All formulae after 28 and 90 days of curing exhibit similar level of flexural strength. In most of investigated samples, flexural strength after 90 days of hydration is slightly higher than strength after 28 days. It is most probably the effect of developing the fibrous forms of hydrates, including fibrous ettringite which in high amounts favourably influences flexural strength in cements containing much of slag [27].

Relation between compressive strength and composition of pastes is not completely confirmed in tests conducted on mortars containing fly ash-slag binders. Research described in [20] shows increase of compressive strength, in case of mortars kept in water during time of curing, along with increase of fly ash added, but only up to $50 \%$. It is probably 

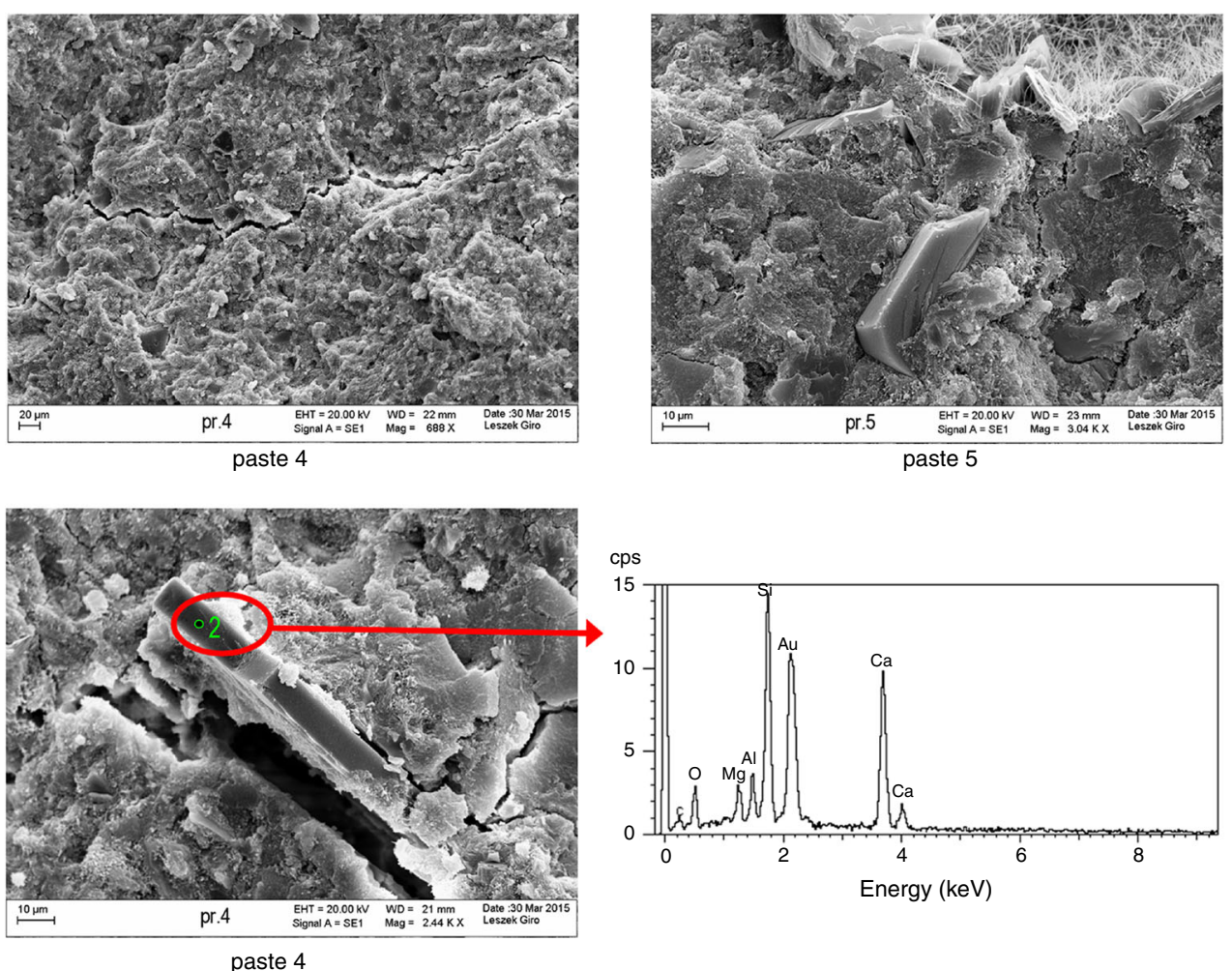

Fig. 11 Visible cracks in samples 4 and 5; elemental spectrum of selected phase

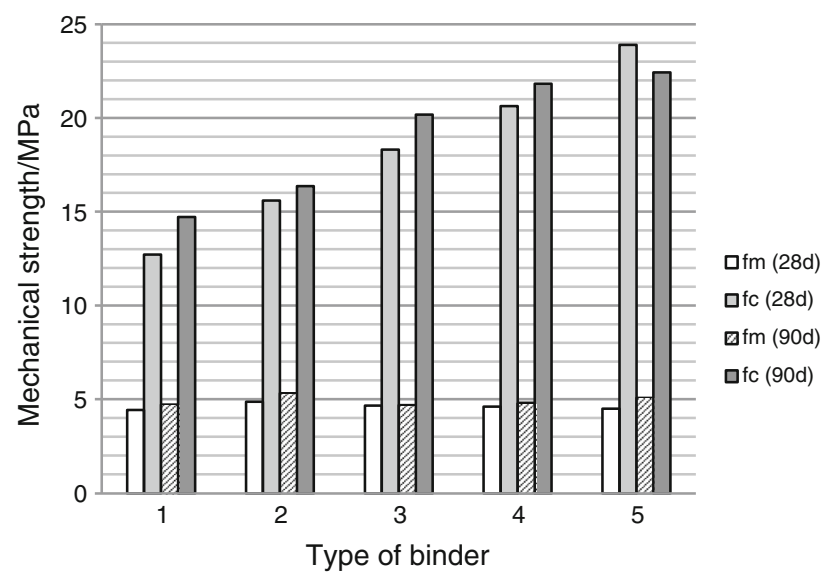

Fig. 12 Compressive (fc) and flexural (fm) strength of fly ash-slag pastes after 28 and 90 days of curing

the effect of difference in shape of microstructure in pastes which hardens in bigger mass compared to paste bonding sand grains in mortar. The structure of paste may be more or less described as homogenous, when mortar fine aggregate appears and transitional area between aggregate and paste is formed. Transitional area is weaker. When sample is loaded appearing stress causes breaks of connection between paste and aggregate, and cracks form on surface of aggregate grains through paste [27]. It is possible that in case of mortar samples with 60 and $70 \%$ of fly ash forces of bonds between paste and aggregate are low and favour propagation of cracks. This conclusion is confirmed by SEM observations of pastes microstructure: the more of fly ash in pastes the more porous and cracked structure the sample has.

Fly ash-slag mortars containing the highest amount of fly ash (70\%) show decrease of compressive strength after 90 days of curing compared to results obtained after 28 days [20]. It confirms the conclusions drawn in the paper and concerning fly ash-slag pastes. It may be the effect of ettringite formation and its expansion. According to one of the theories of expansion, it is caused by forming of big, compacted crystals of ettringite around the grains of aggregate [27]. It probably took place in fly ash-slag mortars. Favourable conditions for ettringite formation in transitional area could take place also in case of mortars containing $60 \%$ of fly ash in binder and kept in water during time of curing. As the effect of clear increase in compressive strength of mortars was not observed in time of curing (between 28 and 90 days). 


\section{Conclusions}

The hydration products as well as the properties of fly ashslag binders mixed in five proportions of components (without chemical activator of slag binding reaction) were studied after 28 and 90 days of curing. The main conclusions are as follows:

1. Investigation of properties of fly ash-slag pastes after 28 and 90 days of curing in water shows that mixes bind and harden due to formation of products similar to those characteristic of cement hydration. These mixes may be considered as non-clinker binders as alternative to cement.

2. In examined mixes, the hydration processes take place mainly until 28th day of hydration. Between 28th and 90th day, further water binding and strength development occur.

3. The more CFBC fly ash incorporated in mixes, the higher the amount of bound water observed until 90th day of hydration.

4. Qualitative composition of hydration products is similar in all examined samples. Main hydration products are: $\mathrm{C}-\mathrm{S}-\mathrm{H}$ phase and ettringite-like phase, and in lower amounts aluminates and aluminosilicates of $\mathrm{C}-\mathrm{A}-\mathrm{H}$ and $\mathrm{C}-\mathrm{A}-\mathrm{S}-\mathrm{H}$ type and also aluminosilicate phases with magnesium. Investigated compositions revealed calcium carbonate entered with components of pastes and forming as effect of carbonation.

5. Microstructure of examined fly ash-slag pastes is not uniform and exhibits various forms of hydrates. C-S$\mathrm{H}$ phase is dense, weakly crystallized, and fibrous form of $\mathrm{C}-\mathrm{S}-\mathrm{H}$ phase growing on spherical conglomerates appears. Ettringite is mainly in the form of needles crystallizing in pores and filling them. Pastes with higher amount of CFBC fly ash exhibit more porous structure.

6. Compressive strength of tested samples increases in time along with increasing amount of fly ash in pastes and, in case of most of samples, in time of hydration. Compressive strength of pastes with the highest amount of fly ash decreases between 28 and 90 days of curing. Despite that fact, investigated sample shows the highest value of compressive strength after 90 days of curing.

7. Obtained results show that investigated mixes of fly ash and slag may be considered as non-clinker binders and further research should be conducted. Research should be continued to optimize the composition of mixes to improve the properties of mortars and concretes composed of such binder.
Open Access This article is distributed under the terms of the Creative Commons Attribution 4.0 International License (http://crea tivecommons.org/licenses/by/4.0/), which permits unrestricted use, distribution, and reproduction in any medium, provided you give appropriate credit to the original author(s) and the source, provide a link to the Creative Commons license, and indicate if changes were made.

\section{References}

1. Klemczak B, Batog M. Heat of hydration of low-clinker cements. J Therm Anal Calorim. 2016;123:1351-60.

2. Han F, Zhang Z, Liu J, Yan P. Hydration kinetics of composite binder containing fly ash at different temperatures. J Therm Anal Calorim. 2016;124:1691-703.

3. Palou MT, Kuzielová E, Žemlička M, Boháč M, Novotný R. The effect of curing temperature on the hydration of binary Portland cement. J Therm Anal Calorim. 2016;125:1301-10.

4. Shuhua L, Yaning K, Lu W. A comparison of hydration properties of cement-low quality fly ash binder and cement-limestone powder binder. J Therm Anal Calorim. 2014;116:937-43.

5. Zhao F-Q, Ni W, Wang H-J, Liu H-J. Activated fly ash/slag blended cement. Resour Conserv Recycl. 2007;52:303-13.

6. Bilim C, Atiş CD. Alkali activation of mortars containing different replacement levels of ground granulated blast furnace slag. Constr Build Mater. 2012;28:708-12.

7. Puertas F, Martínez-Ramírez S, Alonso S, Vásquez T. Alkaliactivated fly ash/slag cement. Strength behaviour and hydration products. Cem Concr Res. 2000;30:1625-32.

8. Criado M, Aperador W, Sobrados I. Microstructural and mechanical properties of alkali activated Colombian raw materials. Materials. 2016;9:1-16.

9. EN 450-1:2012. Fly ash for concrete. Definition, specifications and conformity criteria. BSI. 2012.

10. Rajczyk K. Fly ashes from fluidal boilers and possibilities of their properties improvement. Wyd. Inst. Śl. 2012 (in Polish).

11. Brandt $\mathrm{M}$, editor. Utilization of fly ashes from circulating fluidal bed combustion in construction concrete. Pol Acad Sci Com Civil Eng. 2010 (in Polish).

12. Sheng G, Li Q, Zhai J. Investigation on the hydration of CFBC fly ash. Fuel. 2012;98:61-6.

13. Pacewska B, Blonkowski G, Wilińska I. Studies on the pozzolanic and hydraulic properties of fly ashes in model systems. J Therm Anal Calorim. 2008;94:469-76.

14. Li X, Chen Q, Huang K, Ma B, Wu B. Cementitious properties and hydration mechanism of circulating fluidized bed combustion (CFBC) desulfurization ashes. Constr Build Mater. 2012;36: $182-1187$.

15. Bakharev T, Sanjayan JG, Cheng YB. Resistance of alkali-activated slag concrete to acid attack. Cem Concr Res. 2003;33: 1607-11.

16. Bakharev T, Sanjayan JG, Cheng YB. Sulfate attack on alkaliactivated slag concrete. Cem Concr Res. 2002;32:211-6.

17. Han F, Zhang Z, Liu J, Yan P. Hydration kinetics of composite binder containing fly ash at different temperatures. J Therm Anal Calorim. 2016;124:1691-703.

18. Scholer A, Lothenbach B, Winnefeld F, Zajac M. Hydration of quaternary Portland cement blends containing blast furnace slag, silicious fly ash and limestone powder. Cem Concr Comp. 2015;55:374-82. 
19. Dung NT, Chang T-P, Chen C-T, Yang T-R. Cementitious properties and microstructure of an innovative slag eco-binder. Mater Struct. 2016;49:2009-24.

20. Machowska A. Mechanical and absorption properties of mortars made from fly ash/slag binder. Circ Econ. 2016;135-46 (in Polish).

21. Kabała J, Listkiewicz J. Influence of stabilization of chemical, physical and quantitative composition of by-products of coal combustion and desulfurization process in fluidized boilers on possibility of use. Konf Fluidized combustion of fuels in power industry. Złotniki Lubańskie. 2004 (in Polish).

22. Glinicki M, Ładyżyński K. Activated fly ash from fluidized combustion-new additive for concretes. Konf Sci Technol, Jadwisin. 2002 (in Polish).

23. EN 196-1:2006. Methods of testing cement. Determination of strength.

24. Ben Haha M, Lothenbach B, Le Saout G, Winnefeld F. Influence of slag chemistry on the hydration of alkali-activated blast-furnace slag_-part II: effect of $\mathrm{Al}_{2} \mathrm{O}_{3}$. Cem Concr Res. 2012;42:74-83.

25. Sheng G, Li Q, Zhai J. Investigation on the hydration of CFBC fly ash. Fuel. 2012;98:61-6.

26. Shen Y, Qian J, Zhang Z. Investigations of anhydrite in CFBC fly ash as cement retarders. Constr Build Mater. 2013;40:672-8.

27. Kurdowski W. Cement and concrete chemistry. Springer; 2014.

28. Ben Haha M, Lothenbach B, Le Saout G, Winnefeld F. Influence of slag chemistry on the hydration of alkali-activated blast-furnace slag-part I: effect of MgO. Cem Concr Res. 2011;41: 955-63.

29. Yang K-H, Cho A-R, Song J-K, Nam S-H. Hydration products and strength development of calcium hydroxide-based alkali-activated slag mortars. Constr Build Mater. 2012;29:410-9.

30. Gruskovnjak A, Lothenbach B, Winnefeld F, Figi R, Ko S-C, Adler M, Mäder U. Hydration mechanisms of super sulphated slag cement. Cem Concr Res. 2008;38:983-92.
31. Fernández-Carrasco L, Torrens-Martín D, Morales LM, Martínez-Ramírez S. Infrared spectroscopy in the analysis of building and construction materials. Infrared Spectrosc Mater Sci Eng Technol InTech. 2012;369-382. http://www.intechopen.com/ books/infrared-spectroscopy-materials-scienceengineering-andtechnology/infrared-spectroscopy-of-cementitious-materials.

32. Mendes A, Gates WP, Sanjayan JG, Collins F. NMR, XRD, IR and synchrotron NEXAFS spectroscopic studies of OPC and OPC/slag cement paste hydrates. Mater Struct. 2011;44:1773-91.

33. Mozgawa W, Deja J. Spectroscopic studies of alkaline activated slag geopolymers. J Mol Struct. 2009;924-926:434-41.

34. Uliasz-Bocheńczyk A, Gawlicki M, Mokrzycki E, Pyzalski M. Polymorphic forms of $\mathrm{CaCO}_{3}$ as carbonation product of cement pastes. Min Res Man. 2013;29:79-88 (in Polish).

35. Mozgawa W, Krol M, Dyczek J, Deja J. Investigation of the coal fly ashes using IR spectroscopy. Spectrochim Acta Part A Mol Biomol Spectrosc. 2014;132:889-94.

36. Y1lmaz B, Olgun A. Studies on cement and mortar containing low-calcium fly ash, limestone, and dolomitic limestone. Cem Concr Comp. 2008;30:194-201.

37. Li X-G, Chen Q-B, Huang K-Z, Ma B-G, Wu B. Cementitious properties and hydration mechanism of circulating fluidized bed combustion (CFBC) desulfurization ashes. Constr Build Mater. 2012;36:182-7.

38. Deja J. Durability of alkali-activated slag mortars and concretes. Papers of the Commission on Ceramic Science. Polish Bulletin of Ceramics, Kraków. 2004;83 (in Polish).

39. Puertas F, Fernández-Jiménez A. Mineralogical and microstructural characterization of alkali-activated fly ash/slag pastes. Cem Concr Comp. 2003;25:287-92. 